\title{
Three dimensional velocity structure around aftershock area of the 2004 mid Niigata prefecture earthquake (M6.8) by the Double-Difference tomography
}

\author{
Masahiro Korenaga $^{1}$, Satoshi Matsumoto ${ }^{2}$, Yoshihisa Iio $^{3}$, Takeshi Matsushima ${ }^{2}$, Kenji Uehira ${ }^{2}$, and Takuo Shibutani ${ }^{3}$ \\ ${ }^{1}$ Graduate School of Sciences, Kyushu University, Shin' yama, Shimabara, Nagasaki 855-0843, Japan \\ ${ }^{2}$ Institute of Seismology and Volcanology, Faculty of Science, Kyushu University, Japan, Shin' yama, Shimabara, Nagasaki 855-0843, Japan \\ ${ }^{3}$ Research Center for Earthquake Prediction, Disaster Prevention Research Institute, Kyoto University, Gokasho, Uji, Kyoto 611-0011, Japan
}

(Received February 15, 2005; Revised April 15, 2005; Accepted April 18, 2005)

\begin{abstract}
The 2004 mid Niigata prefecture earthquake with M6.8 occurred in the north of central part of Japan. It was a reverse fault by the regional compression stress field in NW-SE direction. Several aftershocks with $M \geq 6$ were occurred. The large aftershocks occurred on plural fault planes. The plane was either parallel or normal to the main shock one. We estimated three dimensional velocity structures in and around the focal area of the earthquake by using a Double Difference tomography method. The arrival time data were picked from seismograms at the deployed seismic stations settled by Kyoto and Kyushu universities in collaboration, NIED, ERI, and JMA. The velocity structure showed that a low velocity zone existed in the northwest part of the aftershock area. On the contrary, the velocity in the southeast became high. Moreover, the fault plane of the main shock inferred from the aftershock distribution was located at the velocity boundary.
\end{abstract}

Key words: Velocity structure, DD tomography, 2004 mid Niigata, prefecture earthquake.

\section{Introduction}

The 2004 mid Niigata prefecture earthquake with M6.8 occurred in the north of central part of Japan on October 23, 2004. The residents and their infra-structures of this area had been damaged by the earthquake. One of the reasons for the damage was an occurrence of several large aftershocks with $M \geq 6$. The aftershocks were not only located on the fault plane of the main shock, but also on the conjugate plane and a plane parallel to the main shock. There were some studies on the aftershock distribution (i.e. Aoki et al., 2005; Sakai et al., 2005; Shibutani et al., 2005; Kato, 2005). They showed an existence of the plural fault in the aftershock area based on the geometry of the aftershock distribution. According to a detailed study of the hypocenter distribution (Shibutani et al., 2005), at least three or four different fault planes of the large events could be recognized. It is necessary to study a relationship between such a complicated structure of the fault planes and the inhomogeneous structure of the area. Velocity structures around hypocentral area of the large intra-plate earthquakes had been estimated through the tomographic approach by many researches. Recently, a Double Difference (DD) seismic tomography method had been developed by Zhang and Thurber (2003). The DD tomography has been advantageously employed to estimate the inhomogeneous structure around hypocenters in detail by calculating absolute and relative arrival times. Several research studies were followed by using this method. For instance, Okada et al. (2005a) estimated a velocity structure in the region of the

Copy right(c) The Society of Geomagnetism and Earth, Planetary and Space Sciences (SGEPSS); The Seismological Society of Japan; The Volcanological Society of Japan; The Geodetic Society of Japan; The Japanese Society for Planetary Sciences; TERRAPUB
2003 Northern Miyagi Earthquake. They concluded that the earthquake occurred at a velocity boundary formed by the ascent normal faulting with the following reverse faulting. In the present study, we attempt to estimate a velocity structure of the hypocentral area of the 2005 mid Niigata prefecture earthquake by means of the DD tomography algorithm developed by Zhang and Thurber (2003).

\section{Data and Analysis}

After the occurrence of the main shock, in order to determine the precise aftershock location, we started with a temporal seismic observation in the aftershock area of the earthquake. Several seismic stations had been set up in this region by the National Institute for Earth Science and Disaster Prevention (NIED), Earthquake Research Institute, University of Tokyo (ERI), and the Japan Meteorological Agency (JMA) respectively. Figure 1 shows the distribution of the stations. The seismic signals at three stations (TDOM, YMKS, OJKW) are continuously telemetered via satellite to the institutes of Kyushu and Kyoto Universities. The CTOI, CYKN, CYKH, and CHKM are off-line stations at which data are recorded by data loggers. By staffs of the joint observation of Kyoto and Kyushu universities, the arrival time data of $P$ and $S$ wave were picked manually. We used these data for the DD tomography analyses. Shibutani et al. (2005) obtained a detailed hypocenter distribution, station corrections for on-line stations and one dimensional velocity structure through the Joint Hypocenter Determination method. They pointed out that the velocity structure had a strong inhomogeneity just beneath the stations, since the spatial distribution of the station correction factors showed a large deviation. As an initial model, we adopted such velocity structure. The station corrections are 


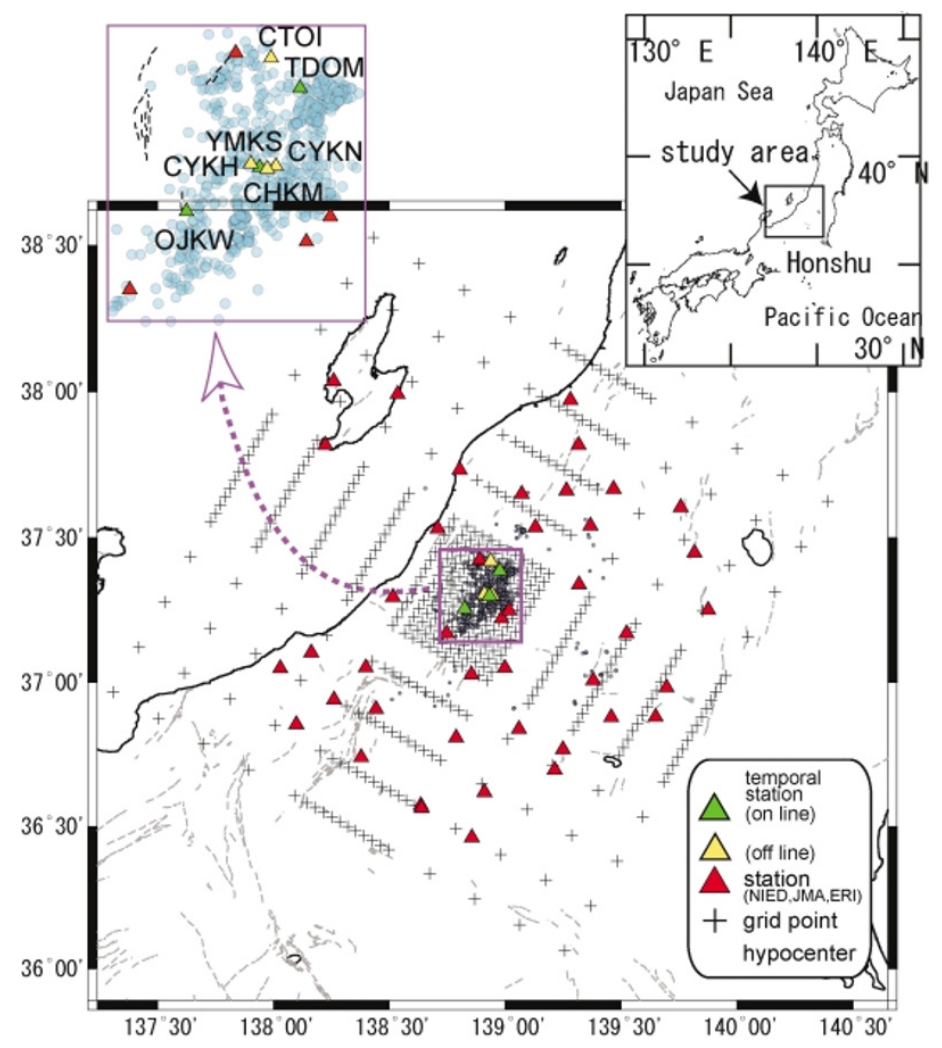

Fig. 1. Map showing station and grid distribution. Cross indicates the location of grid at which velocity is estimated in the tomography. Circle denotes epicenter used in this study. Triangle denotes a location of stations. (Upper right) closed up figure in the aftershock area is shown.

Depth $7.5 \mathrm{~km}$
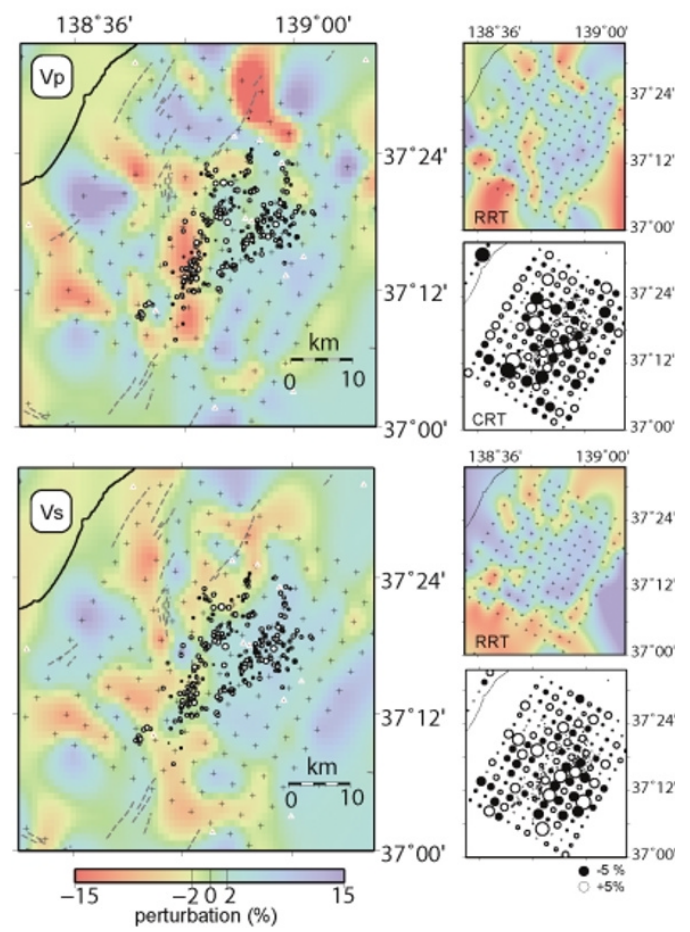

Fig. 2. Velocity perturbations for $P$ and $S$ waves at a depth of $7.5 \mathrm{~km}$. Left maps show the final results. The perturbation is defined as a deviation from average velocity at $7.5 \mathrm{~km}$. Relocated hypocenters with depth of $8-10 \mathrm{~km}$ are plotted by open circles. The CRT velocity perturbation on the grid is plotted on the lower-right side figures. The result of RRT is displayed in the upper-right side. also applied to the arrival time data to avoid probable instability of tomographic inversion. For the off-line station, where the station correction was not available, the station correction are applied from the value taken at the neighboring on-line station. The analysis is separated into two steps. At first, the velocity structure at the sparse grid points with horizontal interval of $20 \mathrm{~km}$ and depth interval of $5 \mathrm{~km}$ was estimated because of the low resolution caused by the sparse station distribution except around the source region. The grids are distributed to have an equal interval in the $\mathrm{N} 30 \mathrm{E}$ and N60W directions. The vertical grids solved in the inversion are set at depths of $0,2.5,7.5,12.5$, and $20 \mathrm{~km}$. Next, we obtain a detail velocity structure in the hypocentral area based on the results of the first step as an initial model. The grid distribution for the second step is shown in Fig. 1. In the hypocentral area, the vertical grid interval is set to 2.5 $\mathrm{km}$. The horizontal one is $3.62 \mathrm{~km}$. By this setting, the grid points are located on the plane with a dip angle of 54 degree. This angle is similar to that of the mainshock fault plane. The vertical grid is set at the depths of $0,2.5,5,7.5$, $10,12.5,15 \mathrm{~km}$. At grids deeper than $15 \mathrm{~km}$, the inversion could not be resolved due probably to the small ray paths contributing those grids. The numbers of $P$ and $S$ wave arrival data picked from 755 earthquakes at 50 stations are 20569 and 19968, respectively. The double differences of 114553 for $P$ and 106836 for $S$ are added to those of the absolute arrival data. 


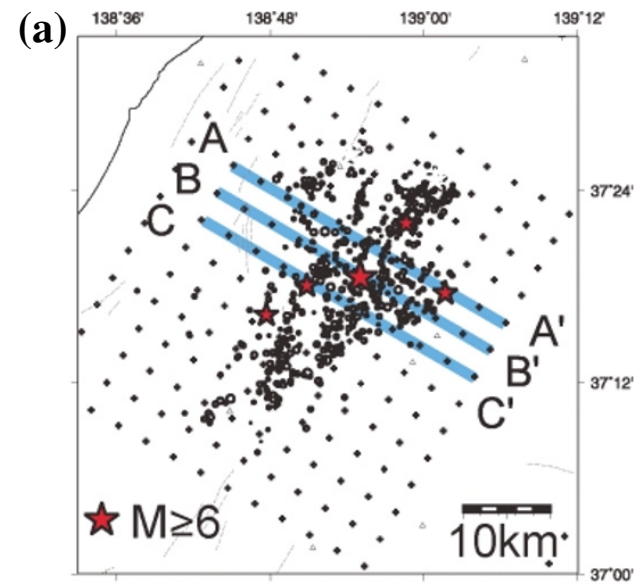

(b)

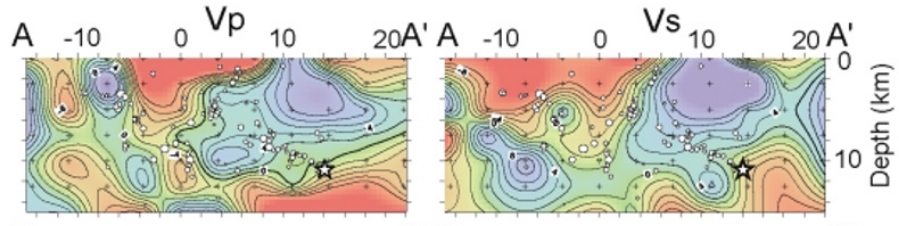

B

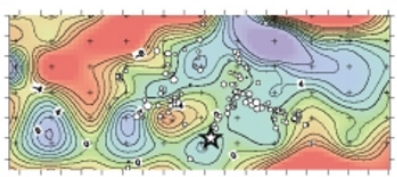

C

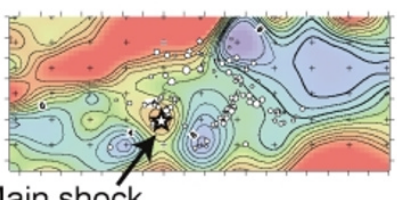

Main shock
B' B

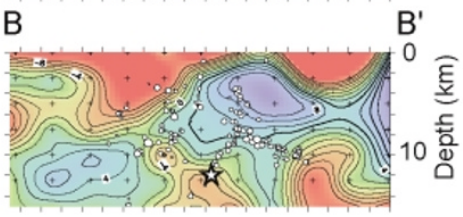

C' C

C

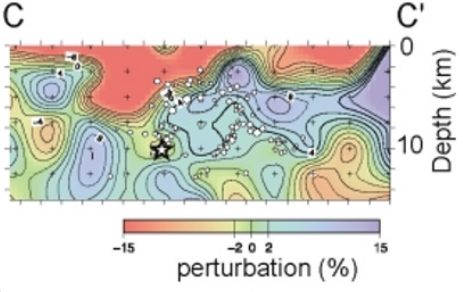

\section{$\widehat{\bar{\xi}}$
嬉
व}
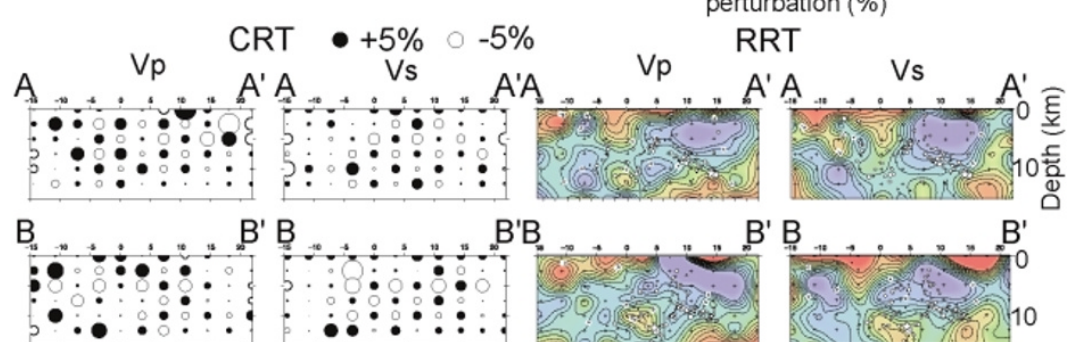

B' B $\mathrm{B}^{\prime} \mathrm{B}$

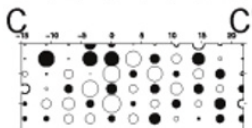

$C^{\prime} \mathrm{C}$

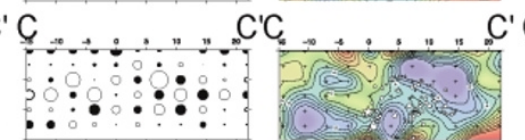

$\mathrm{B}^{\prime} \mathrm{B}$

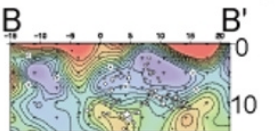

'

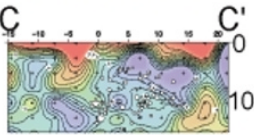

Fig. 3. Vertical cross section of the velocity perturbation normal to the fault plane. (a) The sections are taken along the line A-A', B-B' and C-C'. Star shows the event with $\mathrm{M} \geq 6$. Open circle and cross are the epicenter and grid points, respectively. b) The perturbation plotted in velocity among grids at each depth. The sections for A-A', B-B' and C-C contain the hypocenter of the main shock, the largest aftershock, and the event on the conjugate fault, respectively. Solid circle and stars are the same as in Fig. 2. Star indicates the event with M $\geq 6$. The results of CRT and RRT are shown in lower of the figure.

\section{Results}

Final results are obtained after 17 and 29 times' iteration for the first and the second steps of the inversion. The root mean square residual (rms) finally became $0.064 \mathrm{sec}$ from the initial rms residual of $0.950 \mathrm{sec}$. Figure 2 shows the velocity structure at a depth of $7.5 \mathrm{~km}$. Both $P$ and $S$ wave velocities are shown. To check the resolution of the inversion, we carried out a checker board resolution test (CRT) and a restoring resolution check (RRT), both of which had been used in the many tomographic studies. In the CRT test, velocity perturbations of $+5 \%$ and $-5 \%$ are assigned to the grid points by turns. RRT for the obtained structure was carried out. Figure 2 shows the results of CRT and RRT. Throughout the both checks, the velocity could be resolved at the hypocentral region. However, the velocity is not resolved well out of the hypocentral region. The high resolution region for $S$ wave slightly shifts to the east in CRT. This could be caused by the larger number of picked arrival 

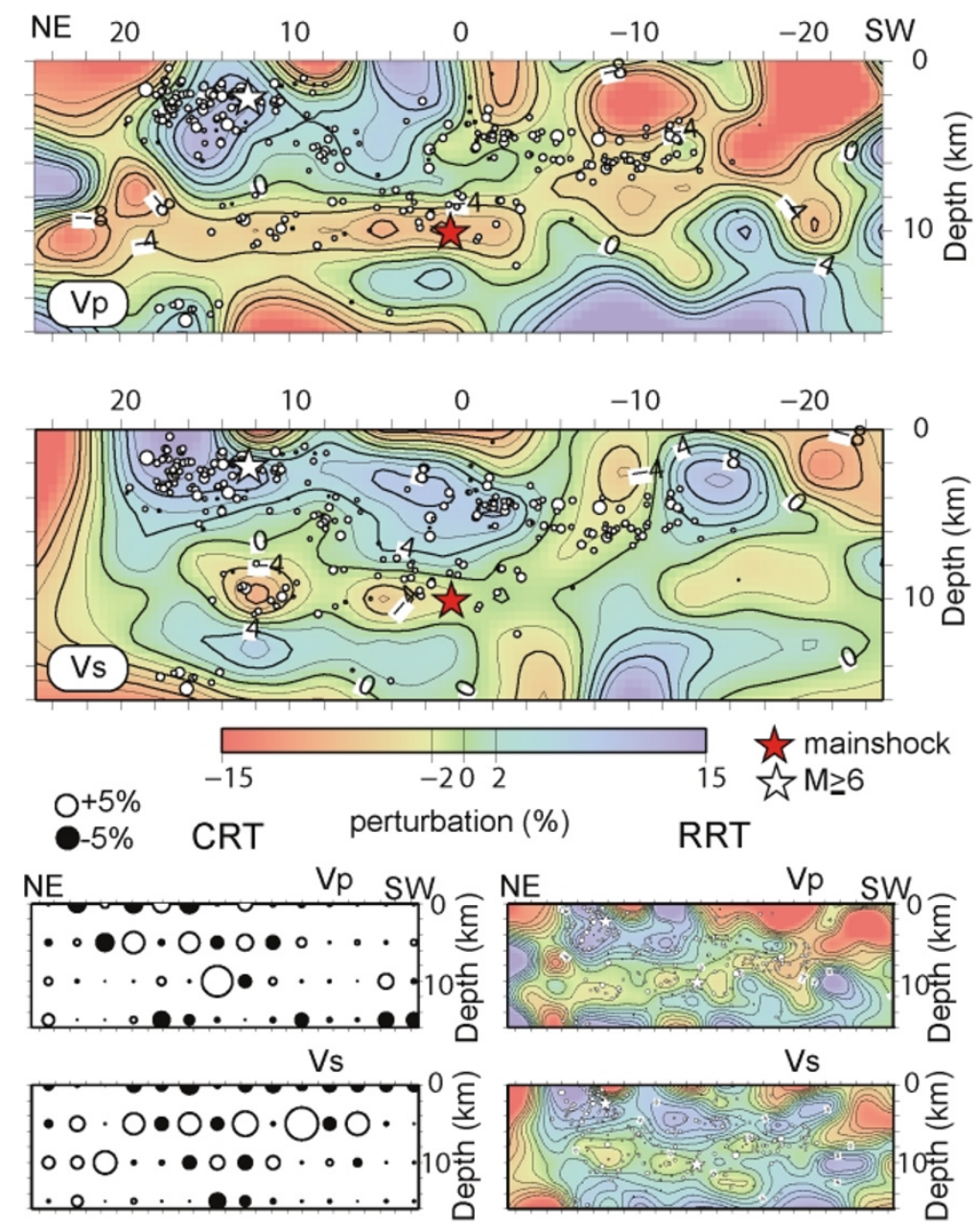

Fig. 4. Velocity perturbation on the main shock fault. Upper and lower figures indicate the perturbations of $P$ and $S$ wave velocity, respectively. The results of CRT and RRT are shown in lower of the figure.

time of $S$ wave at the station located in the western part of the network. At these stations, a high frequency component dominated in the seismograms is observed, being due to a high $\mathrm{S} / \mathrm{N}$ ratio. Therefore, the arrival time data of $S$ wave can be obtained easily. Then the velocity in the western part can be resolved well.

At a $7.5 \mathrm{~km}$ depth, the low velocity region is distributed in the west of the aftershock area. Figure 3 shows $P$ and $S$ wave velocity perturbations on the vertical cross sections normal to the fault plane strike along the line displayed in Fig. 3(a). The sections included the hypocenter of the main shock, the largest aftershock, and the large after shock on the conjugate fault plane. From comparisons of the results with the CRT and RRT, the velocity structure is resolved around the hypocenters. The low velocity region is found in the hanging wall of the main shock fault. The velocity becomes high at the opposite side of the fault. It seems that the main shock faulting occurred at the edge of high velocity region. We can also see a feature in which the initiation points of the large earthquakes noted by stars in Fig. 3 are located in the area with a relatively low velocity. This feature is clear for a $S$ wave velocity structure. The hypocenters plotted in the figure are relocated by the inversion scheme. The hypocenters are distributed on the fault plane of the large events. The velocity perturbations for $P$ and $S$ waves on and around the fault of the main shock are displayed in Fig. 4. The cross section, which almost coincided with the fault plane of the main shock, is taken to include the hypocenter of the main shock. In this figure, the velocity distribution on the fault is inhomogeneous. It seems that the aftershocks are located in the high or medium velocity region. In addition, the velocity becomes relatively lower at the hypocenter of the main shock.

\section{Discussions}

From the velocity distribution on the fault plane as seen in Fig. 4, the high velocity part appears at a shallower NE part of the fault plane more than the hypocenter of the main shock. According to the slip distribution of the fault (Honda et al., 2005), the large slip occurred at and just above the hypocenter. Comparing this slip distribution with the velocity one, the large slip area corresponds to the high velocity region.

In the tomographic inversion, the hypocenters are relocated. Figure 5 shows a map view and a vertical cross sections of both initial and relocated hypocenters used in this study along $\mathrm{X}-\mathrm{X}^{\prime}$. The hypocenters shift to the westward after the relocation. It is considered that this move of hypocenter is mainly caused by the existence of a low velocity region in shallower NW part. In addition, the distribu- 


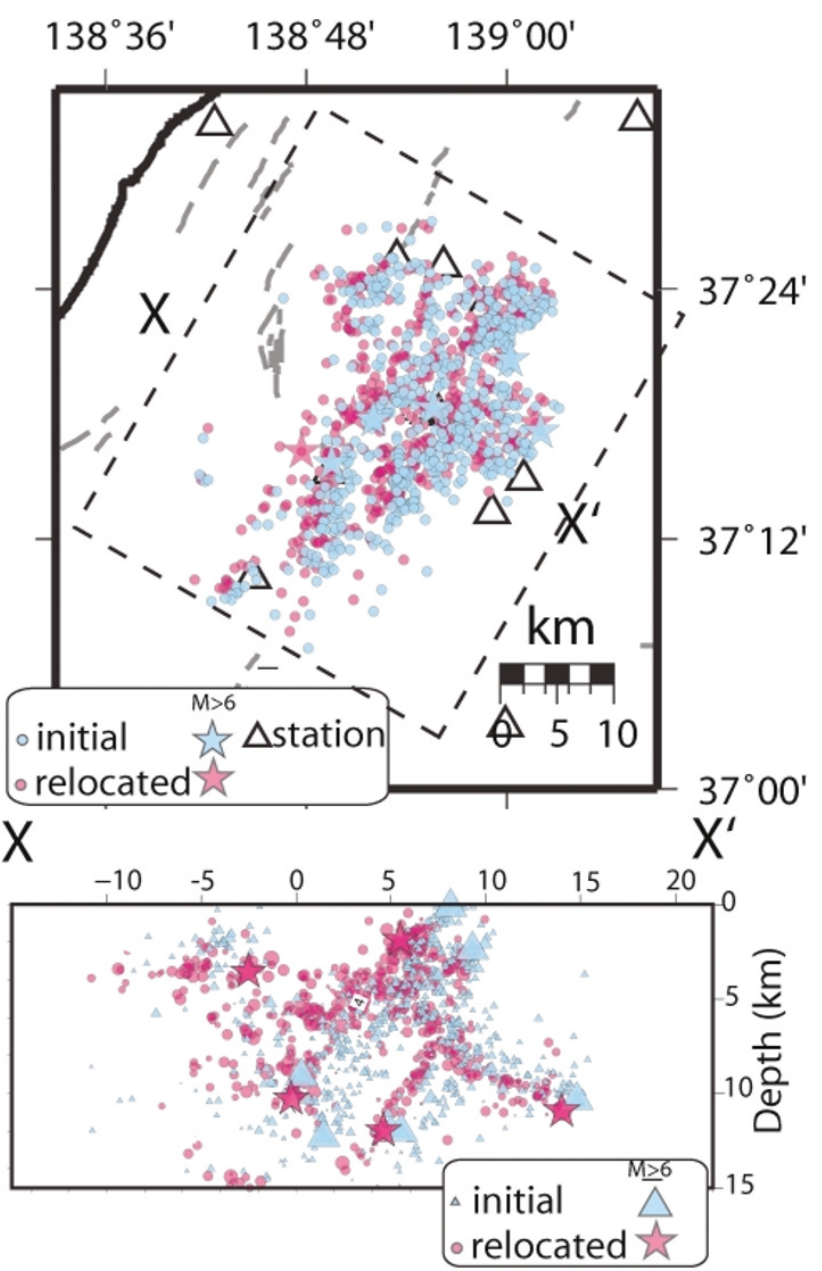

Fig. 5. Hypocenter distribution before and after the tomographic inversion. Blue symbol shows initial location of hypocenter. Relocated hypocenters are indicated by the red symbols.

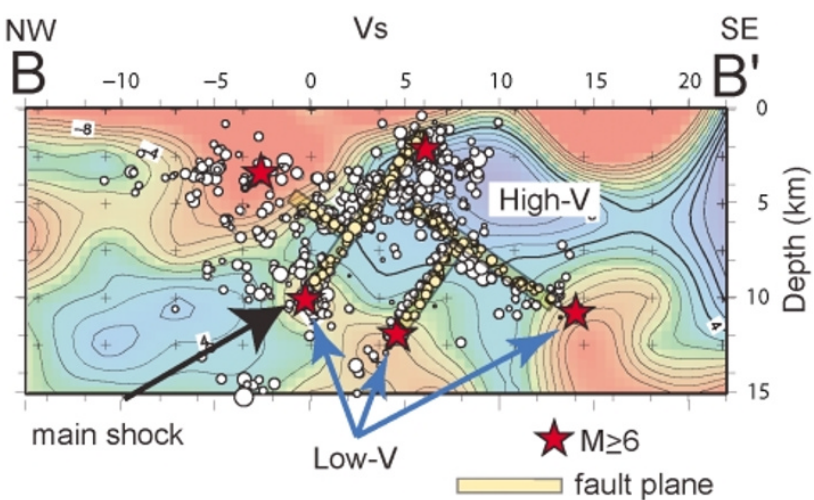

Fig. 6. An interpretation of the hypocenter distribution and the velocity structure. Projected hypocenters on the normal plane to the fault are relocated based on the obtained velocity structure. The cross section is the same as B-B' for $S$ wave velocity in Fig. 3.

tion becomes less scattering. The image of the plural faults becomes clear by the DD tomography. Figure 6 shows the relocated hypocenters in Fig. 5 and the B-B' cross section of velocity perturbation shown in Fig. 3. From this figure, we can also see the ruptures of the large events initiated in the regions with a low velocity. It also seems that the veloc- ity in the hanging wall side of the main shock fault is low. The velocity contour condenses around the fault plane of the main shock. This implies a possibility that the main shock fault is located in the velocity transition zone from low to high. This feature is similar to the study in the 2003 northern Miyagi earthquake reported by Okada et al. (2005a).

Okada et al. (2005b) and Kato et al. (2005) estimated the velocity structure in this region. By applying the DD tomography technique, they also analyzed different datasets taken from many off-line stations. When compared our result to those of them, the general features of the velocity structure were almost similar.

Acknowledgments. We are indebted to the participants to the joint observation by Kyoto and Kyushu Universities for their cooperation. The helpful comments and suggestions of Profs. Hasemi, Kosuga, and Hirata on preliminary version of the article are gratefully acknowledged. We use seismic data observed by NIED, ERI and JMA. We used the program for the Double Difference Tomography by Zhang and Thurber (2003). We wish to thank Dr. Okada for many helpful and valuable suggestions with the Double Difference Tomography. This work was supported by the Grant-in-Aid for Special Purposes (16800054).

\section{References}

Aoki, S., M. Nishi, K. Nakamura, T. Hashimoto, S. Yoshikawa, H. M. Ito, Multi-planar structures in the aftershock distribution of the Mid Niigata prefecture Earthquake in 2004, Earth Planets Space, 57, this issue, 403409, 2005.

Kato, A., E. Kurashimo, N. Hirata, T. Iwasaki, and T. Kanazawa, Imaging the source region of the 2004 Mid-Niigata prefecture earthquake and the evolution of a seismogenic thrust-related fold, Geophys. Res. Lett, 2005 (in press).

Honda, R., S. Aoi, N. Morikawa, H. Sekiguchi, T. Kunugi, and H. Fujiwara, Ground Motion and Rupture Process of the 2004 Mid Niigata Prefecture Earthquake Obtained from Strong Motion Data of K-NET and KiK-net, Earth Planets Space, 2005 (submitted).

Okada, T., A. Hasegawa, J. Suganomata, N. Umino, H. Zhang, and C. Thurber, Imaging the fault plane and asperities of the 2003 M6.4 northern Miyagi earthquake, NE Japan, by double-difference tomography, Earth. Planet. Sci. Lett., 2005a (submitted).

Okada, T., N. Umino, T. Matsuzawa, J. Nakajima, N. Uchida, T. Nakayama, S. Hirahara, T. Sato, S. Hori, T. Kono, Y. Yabe, K. Ariyoshi, S. Gamage, J. Shimizu, J. Suganomata, S. Kita, S. Yui, M. Arao, S. Hondo, T. Mizukami, H. Tsushima, T. Yaginuma, A. Hasegawa, Y. Asano, H. Zhang, and C. Thurber, Aftershock distribution and 3D seismic velocity structure in and around the focal area of the $2004 \mathrm{mid}$ Niigata prefecture earthquake obtained by applying double-difference tomography to dense temporary seismic network data, Earth Planets Space, 57, this issue, 435-440, 2005b.

Sakai, S., N. Hirata, A. Kato, E. Kurashimo, T. Iwasaki, and T. Kanazawa, Multi-fault system of the 2004 Mid-Niigata Prefecture Earthquake and its aftershocks, Earth Planets Space, 57, this issue, 417-422, 2005.

Shibutani, T., Y. Iio, S. Matsumoto, H. Katao, T. Matsushima, S. Ohmi, F. Takeuchi, K. Uehira, K. Nishigami, B. Enescu, I. Hirose, Y. Kano, Y. Kohno, M. Korenaga, Y. Mamada, M. Miyazawa, K. Tatsumi, T. Ueno, H. Wada, and Y. Yukutake, Aftershock Distribution of the 2004 NiigataChuetsu Earthquake $(\mathrm{Mj}=6.8)$ and Heterogeneous Structure in and Around the Source Region, Earth Planets Space, 57, 2005 (submitted).

Zhang, H. and C. Thurber, Double-Difference Tomography: the method and its application to the Hayward Fault, California, Bull. Seism. Soc. Am., 93, 1875-1889, 2003.

M. Korenaga, S. Matsumoto (e-mail: matumoto@sevo.kyushu-u.ac.jp), Y. Iio, T. Matsushima, K. Uehira, and T. Shibutani 